This item was submitted to Loughborough's Research Repository by the author.

Items in Figshare are protected by copyright, with all rights reserved, unless otherwise indicated.

\title{
Computational study of ultrasonically-assisted turning in Ti alloys
}

PLEASE CITE THE PUBLISHED VERSION

http://dx.doi.org/10.4028/www.scientific.net/AMR.223.30

PUBLISHER

(C) Trans Tech Publications

VERSION

AM (Accepted Manuscript)

LICENCE

CC BY-NC-ND 4.0

REPOSITORY RECORD

Muhammad, Riaz, Naseer Ahmed, Murat Demiral, Anish Roy, and Vadim V. Silberschmidt. 2019. "Computational Study of Ultrasonically-assisted Turning in Ti Alloys". figshare.

https://hdl.handle.net/2134/8291. 
This item was submitted to Loughborough's Institutional Repository (https://dspace.lboro.ac.uk/) by the author and is made available under the following Creative Commons Licence conditions.

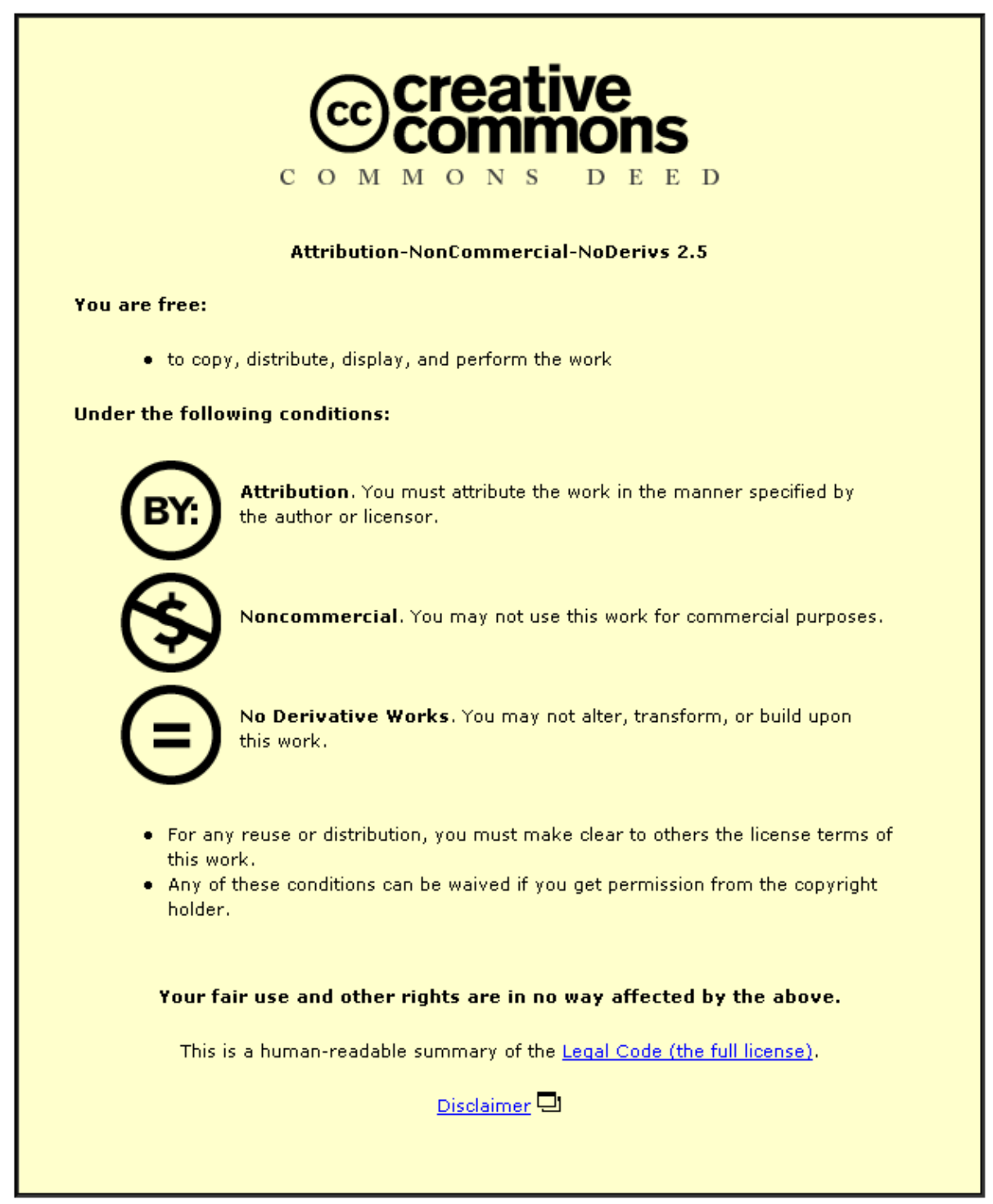

For the full text of this licence, please go to: http://creativecommons.org/licenses/by-nc-nd/2.5/ 


\title{
Computational Study of Ultrasonically-Assisted Turning in Ti alloys
}

\author{
R. Muhammad ${ }^{* a 1}, N$. Ahmed ${ }^{\mathrm{b} 2}$, M. Demiral ${ }^{\mathrm{c} 1}$, A. Roy ${ }^{\mathrm{d} 1}$, V. V. Silberschmidt ${ }^{\mathrm{e} 1}$ \\ Loughborough University, Wolfson School of Mechanical and Manufacturing Engineering \\ Loughborough University, Leicestershire, UK LE11 3TU \\ ${ }^{2}$ Department of Mechanical Engineering, Taibah University, Saudi Arabia

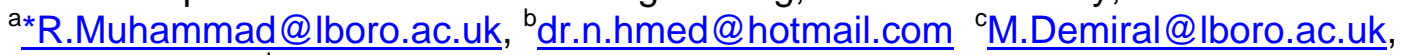 \\ d.Roy3@lboro.ac.uk, ${ }^{\mathrm{e}} \underline{\text {.S.Silberschmidt@lboro.ac.uk }}$
}

\begin{abstract}
:
The industrial applications of titanium alloys especially in aerospace, marine and offshore industries has grown significantly over the years primarily due to their high strength, light weight as well as good fatigue and corrosion-resistance properties. The machinability of these difficult-to-cut metallic materials using conventional turnning (CT) techniques has seen a limited improvement over the years. Ultrasonically-assisted turnning (UAT) is an advanced machining process, which has shown to have specific advantages especially in the machining of high-strength alloys. In this study a three-dimensional finite element model of ultrasonically-assisted oblique cutting of a Ti-based super alloy (Ti15V3Cr3Al3Sn) is developed. The nonlinear temperature-sensitive material behaviour is incorporated in our numerical simulations based on results obtained with split-Hopkinson pressure bar tests. Various contact conditions are considered at the tool tip-workpiece interface to get an indepth understanding of the mechanism influencing the cutting parameters. The simulation results obtained are compared for both CT and UAT conditions to elucidate main deformation mechanisms responsible for the observed changes in the material's responses to cutting techniques.
\end{abstract}

Keywords: Ultrasonically-assisted turnning, Ti alloy, 3D finite elements, oblique cutting.

\section{Introduction}

Titanium alloys offer an enormous application potential within extreme operating conditions in several industrially relevant areas. However, the main obstacle in the application of these alloys in modern industries is that structures and components in $\mathrm{Ti}$ alloys are graded as hard-to-cut materials, particularly in turning [1]. Conventional turnning (CT) of Ti alloys produces high temperature and cutting forces which are the main reason for excessive wear of the cutting edge, pre-mature tool failure and lack of dimensional accuracy. In recent decades, many researchers have contributed to achieve considerable improvements in turnning of modern alloys by using high-speed machining techniques. The development of new cutting techniques is stipulated by the above mentioned deficiencies of CT.

Ultrasonically assisted turnning (UAT) is an advance machining technique, in which up to 40000 low energy impacts are superimposed on the cutting tool (Figure 1). This new machining technique offers significant improvement in the processing of modern alloys [2-6]. Application of ultrasonic vibration to the cutting tool not only reduces cutting forces considerably but also improves the surface finish of a machined workpiece [6-8]. In any machining operation reduction of cutting forces can increase the tool life, reduce residual stresses in the machined workpiece and improve the surface finish. Various parameters of UAT such as a vibration frequency, amplitude of vibration, a direction of ultrasonic vibration, friction at the tool tip-workpiece interface and a cutting speed influence the imposed cutting forces on the tool.
A 3D finite element (FE) model of ultrasonically assisted oblique cutting is developed in DEFORM ${ }^{T M}$ [9] to study the effects of various machining parameters on the cutting forces and to suggest the optimum cutting conditions for the processing of modern Ti alloys.

\section{Finite Element Model}

A 3D thermomechanically coupled oblique cutting model of CT and UAT for Ti alloys is developed to study the effect of various cutting parameters on cutting forces. This model possesses a number of advantages as compared to our previously developed FE models for metal cutting $[5,7,10]$. This model allows us to study the effects of vibration amplitude, frequency and friction conditions on the tool tipworkpiece interface in UAT by using the real tool geometry. In the FE simulation of $\mathrm{Ti}$ alloy, a deformable workpiece with dimension of $2.0 \mathrm{~mm}$ in length, $1.5 \mathrm{~mm}$ in width and $0.5 \mathrm{~mm}$ in height with a depth of cut of $0.3 \mathrm{~mm}$ was used. Four-nodded tetrahedral elements with a minimum element length of $0.05 \mathrm{~mm}$ were used to mesh the workpiece. A rigid cutting tool with a tungsten carbide coating (DNMG150608 supplied by Seco) moving at a speed of 10 $\mathrm{m} / \mathrm{min}$ is modelled in the FE simulation. The material properties defined for the cutting tool were those of tungsten carbide that was discretized with 4-noded 23440 tetrahedral elements with approx. 5500 nodes with a high mesh density in the tool tip-workpiece contact area (Figure 2). The cutting tool had a rake angle $\alpha=7.5^{\circ}$, a back clearance angle $\gamma=5^{\circ}$ and a 
nose radius of $0.79 \mathrm{~mm}$ (Figure 1 ). The ambient temperature is selected as $20^{\circ} \mathrm{C}$ for the cutting tool and workpiece, and the number of simulation steps is kept at 960 with a total time of $0.006 \mathrm{sec}$.

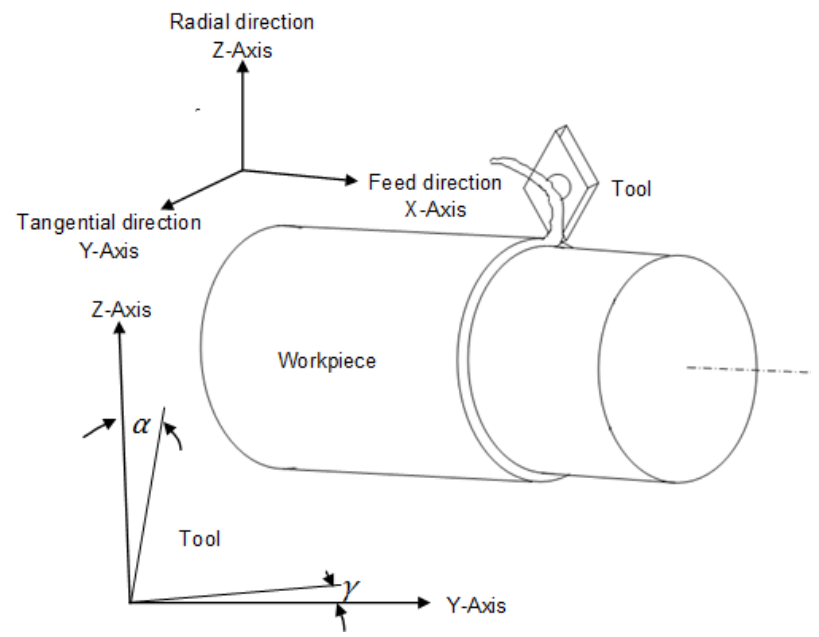

Figure 1: Principal vibration directions of ultrasonically assisted machining

The chip formation process involves substantial plastic deformation in the workpiece material, especially near the cutting tip [11]. As a result, the elements near the cutting tip distort substantially, leading to numerical convergence problems in simulations. The use of the re-meshing techniques helps to mitigate problems with convergence as highly distorted elements are replaced with geometrically consistent ones. To simulate the oblique cutting of the Ti alloy, a harmonic oscillation with amplitude of $10 \mu \mathrm{m}$ to $40 \mu \mathrm{m}$ was superimpose on the tool in the tangential direction (Figure 1).

The path of the cutting tool for UAT is represented by

$d(t)=\left[\frac{L \tau}{t}+a \sin (2 \pi f \tau)\right]$

where $d(t)$ is displacement of the tool with respect to time $t$. $a$ and $f$ are the amplitude and frequency of vibration, respectively. $L$ is the total length of cut for a specific cutting speed in a specific time. $\tau$ is the instantaneous time and $t$ is the total simulation time. In order to compare the advantages of UAT over CT, the numerical simulation are repeated for CT with the same cutting parameter (without any imposed vibration on the cutting tool; i.e. $a=f=0$ ).

\subsection{Material Model}

In order to obtain a stress-strain behaviour of the $\mathrm{Ti}$ alloy (Ti15V3Cr3AI3Sn) under various strain rates and temperatures, a split-Hopkinson test [12] was carried out at Tampere University of Technology, Finland. The material response of the alloy for different strain rates at room temperature obtained in the test is shown in Figure 3. The nonlinear strain-rate and temperature-sensitive material model used in our numerical simulations comprised twelve different stress-strain curves obtained for a combination of four different strain rates $\left(0.1 \mathrm{~s}^{-1}, 1 \mathrm{~s}^{-1}, 3331 \mathrm{~s}^{-1}, 10^{10} \mathrm{~s}^{-1}\right)$ and three different temperature values $\left(20^{\circ} \mathrm{C}, 600^{\circ} \mathrm{C}\right.$, $800^{\circ} \mathrm{C}$ ).

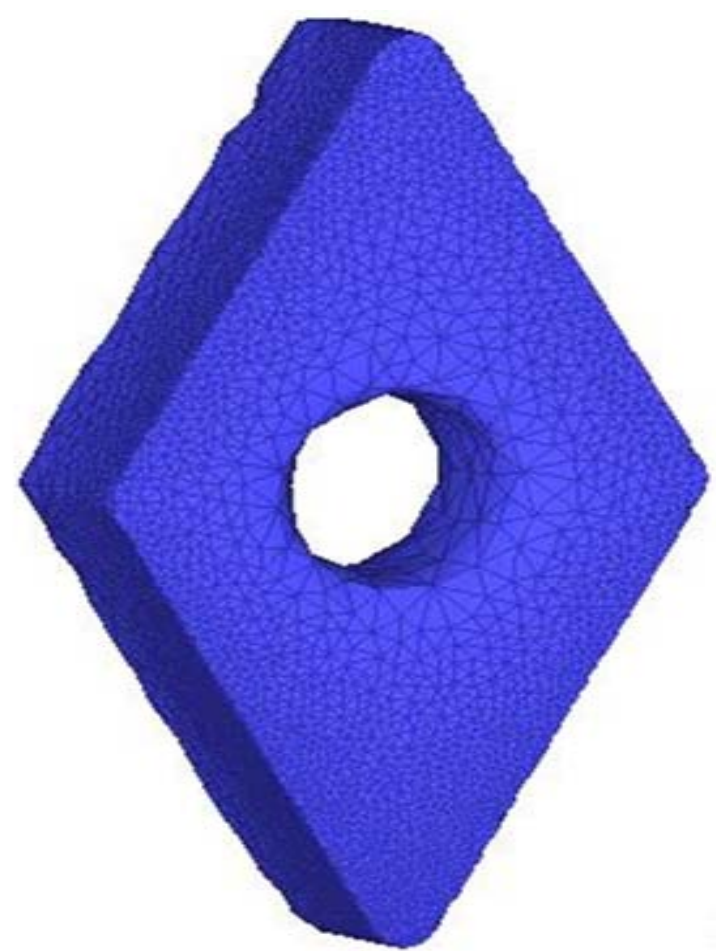

(a)

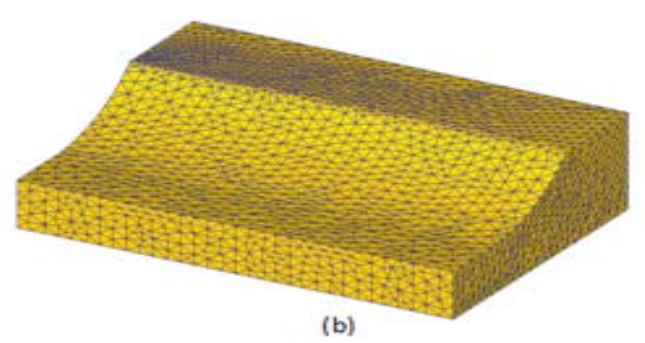

Figure 2: Meshed models of cutting tool (a) and workpiece (b)

These curves were modified in such a way that the magnitudes of stress for high strain levels are limited by the ultimate dynamic tensile stress (UTS) (Figure 4). The material properties of the alloy are $E=87 \mathrm{GPa}$, $v=0.3, \rho=4900 \mathrm{~kg} / \mathrm{m}^{3}$, where $E, v$ and $\rho$ are the Young's modulus, Poisson's ratio and density of the material, respectively. Thermal conductivity of the $\mathrm{Ti}$ alloy is $k=8.08 \mathrm{~W} / \mathrm{m} . \mathrm{K}$. A temperature-dependant thermal expansion and specific heat $\left(C_{p}\right)$ behaviour of the material was incorporated into the model. The details are available elsewhere [13].

\subsection{Friction Model}

The shear friction model is known to better represent the friction process and thus was adopted in our study [9]. The model incorporates a shear friction factor

$m_{f r}=\frac{\tau_{f}}{k_{s}}$

where $k_{s}$ is shear flow stress of the workpiece material at the tool-chip interface and $\tau_{f}$ is frictional 
shear stress [14, 15]. For the idealized condition, $m_{f r}=0$ and for a case of high friction, perhaps, due to a lack of any lubrication (dry condition), $m_{f r}=0.5$ is used in our numerical simulations.

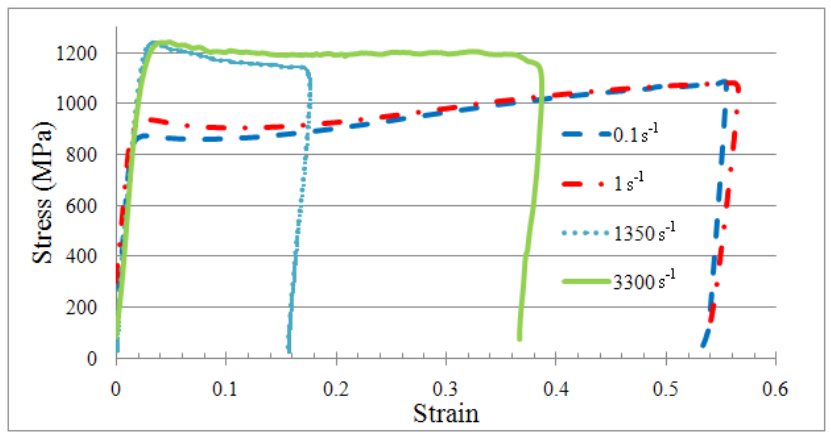

Figure 3: Stress-strain diagrams of Ti15V3Cr3AI3Sn obtained from split-Hopkinson test for different strain rates at room temperature $\left(20^{\circ} \mathrm{C}\right)$

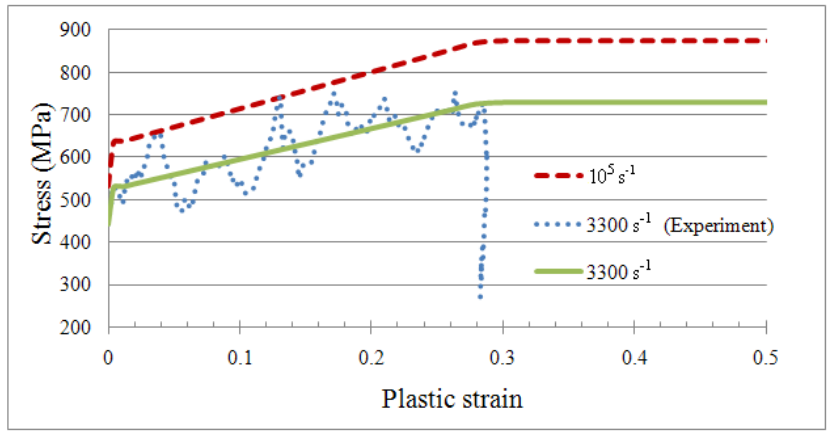

Figure 4: Modified strain-rate-sensitive material model for $600^{\circ} \mathrm{C}$

\section{Results and Discussion}

The FE simulations for the studied $\mathrm{Ti}$ alloy were carried out and the results for UAT and CT are presented and discussed in this section. For all the simulations the cutting parameters such as depth of cut $(0.3 \mathrm{~mm})$, feed rate $(0.1 \mathrm{~mm} / \mathrm{rev})$ and cutting speed $(10 \mathrm{~m} / \mathrm{min})$ were used for both UAT and CT. Two contact conditions, contact without friction $\left(m_{f r}=0\right)$ and contact with friction $\left(m_{f r}=0.5\right)$ were used in simulations [16], to analyze the effect of friction on cutting forces. Similarly, the effect of amplitude and frequency of vibration on cutting forces were also investigated in UAT simulation.

\subsection{Cutting Forces}

Application of ultrasonic vibration to the cutting tool in machining of the Ti alloy brought noticeable amount of reduction in the cutting forces. In CT the cutting tool is in continuous interaction with the workpiece and thus, a constant level of force was observed after the initial stage of the tool engagement and chip formation. In UAT, the vibrating tool causes the forces to fluctuate over a wide range (from zero to a peak force slightly above the forces in CT). Here, only the average values of cutting forces are used for comparison. Figure 5 shows the average radial and tangential component of cutting force for both CT and
UAT. Reductions of $65 \%$ in tangential and $57 \%$ in radial component of forces were observed as compared to the forces in CT.

\subsection{Effect of Vibration Amplitude}

The selection of appropriate amplitude of vibration is critical for UAT. This was investigated by means of FE analysis of UAT. A reduction in cutting forces was observed with the increase in vibration amplitude. An average $25 \%$ reduction in cutting forces was found by the increasing vibration amplitude from $10 \mu \mathrm{m}$ to 30 $\mu \mathrm{m}$ (Figure 6). However, a further increase in amplitude from $30 \mu \mathrm{m}$ to $40 \mu \mathrm{m}$ did not affect the cutting forces significantly causing only a $2 \%$ reduction in cutting forces.

\subsection{Effect of Vibration Frequency.}

The effect of three frequencies $(10 \mathrm{kHz}, 20 \mathrm{kHz}$ and $30 \mathrm{kHz}$ ) was analyzed in the FE simulations of UAT of the $\mathrm{Ti}$ alloy. For all the three cases a reduction in cutting forces with the increase in frequency was observed (Figure 7). An average 36\% reduction in cutting forces occurred when the frequency increased from $10 \mathrm{kHz}$ to $20 \mathrm{kHz}$. A further drop of $5 \%$ in cutting forces was found when the frequency was further increased from $20 \mathrm{kHz}$ to $30 \mathrm{kHz}$. This trend can be explained by the increase in the velocity of the vibrating cutting tool that is proportional to both vibration amplitude and frequency:

$V_{t}=\operatorname{asin}(2 \pi f I)$,

where $f$ is the frequency, $V_{t}$ is the cutting speed and $a$ is the amplitude.

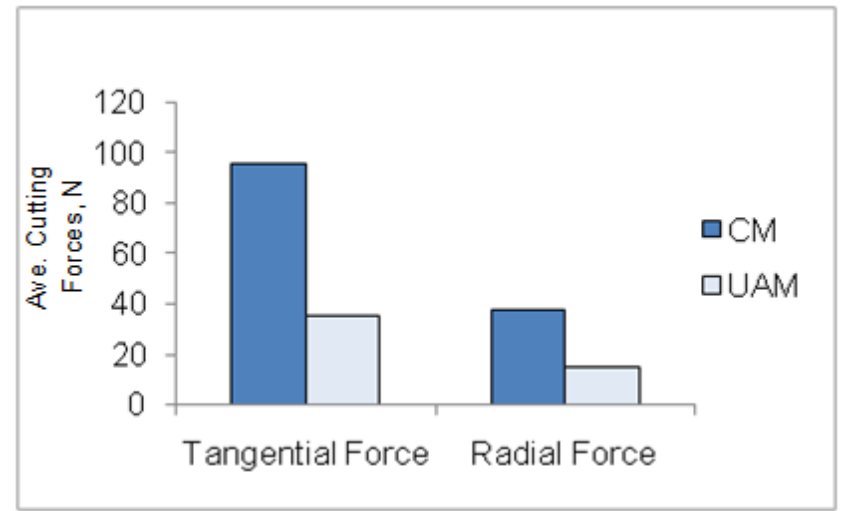

Figure 5: Comparison of forces in CT and UAT in dry cutting (amplitude $30 \mu \mathrm{m}$ and frequency $20 \mathrm{kHz}$ )

\subsection{Temperature Distribution}

Temperature generated in UAT and CT process was also investigated. The temperature in UAT is higher then in CT, the possible causes for this are the effect of the additional factor linked to dissipation of the vibration energy [6]. Figure 8 shows the temperature distribution in the cutting region in UAT. In the simulation of both UAT and $\mathrm{CT}$, a relatively higher temperature was observed along the contact area of tool-workpiece interface. However, in UAT the average temperature of the tool remain lower as 
compared to $\mathrm{CT}$ due to the continual separation between the tool and the workpiece.

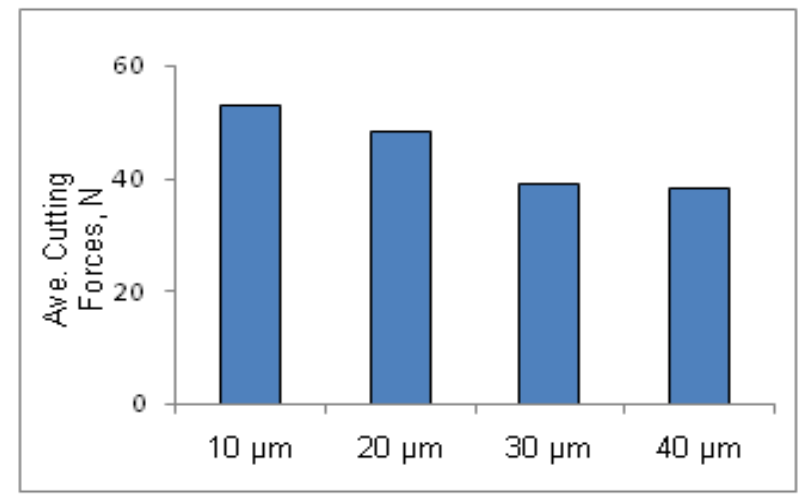

Figure 6: Effect of vibration amplitude on average cutting forces in UAT (frequency $20 \mathrm{kHz}$ )

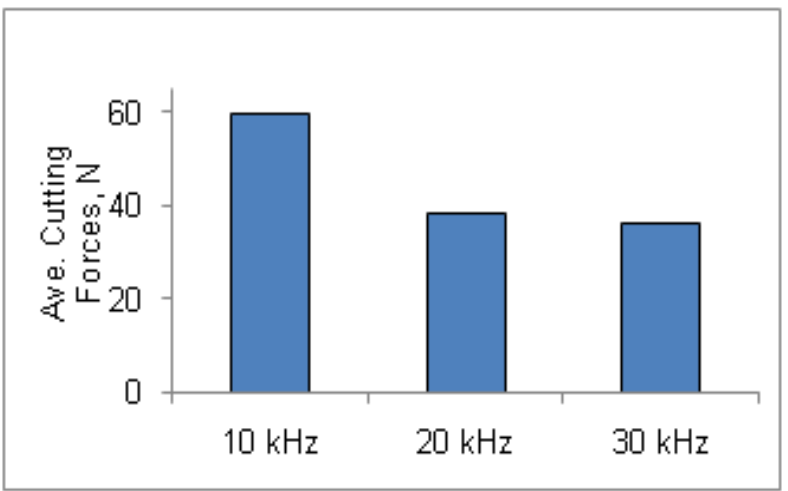

Figure 7: Effect of frequency on cutting forces in UAT (amplitude $30 \mu \mathrm{m}$ )

A frictionless cutting condition was also studied for UAT. A considerable amount of reduction in cutting forces (approx. 30\%) was observed under that condition as compared to the case with the same cutting parameters but dry cutting.

\section{Conclusion}

In this paper, a 3D thermomechanically coupled finite element model for ultrasonically assisted turnning (UAT) and conventional turning (CT) of Ti-based super alloy is studied. The use of 3D geometry of the cutting tool and the introduction of feed rate in FE simulation allow for the study of real-time cutting processes in term of cutting forces and temperature in the process zone. The comparative study of both processes revealed many advantages of UAT as compared to CT.

The following conclusions are derived from the study; 1. Application of ultrasonic vibration to the cutting tool reduced the tangential and radial components of cutting forces (approx. 65\% and 57\%, respectively) as compared to those in CT.

2. The increase in amplitude from $10 \mu \mathrm{m}$ to $30 \mu \mathrm{m}$ caused a decrease of approx. $25 \%$ in average cutting forces for UAT.

3. An average decline of about $36 \%$ in cutting forces was observed with the increase in frequency from 10 $\mathrm{kHz}$ to $20 \mathrm{kHz}$, which can be also attributed to an increased velocity of the tool and a lower time of contact between the tool and chip

4. A $30 \%$ drop in the average cutting forces was observed for a frictionless cutting condition on the tool workpiece interface in UAT when compare to dry cutting condition.

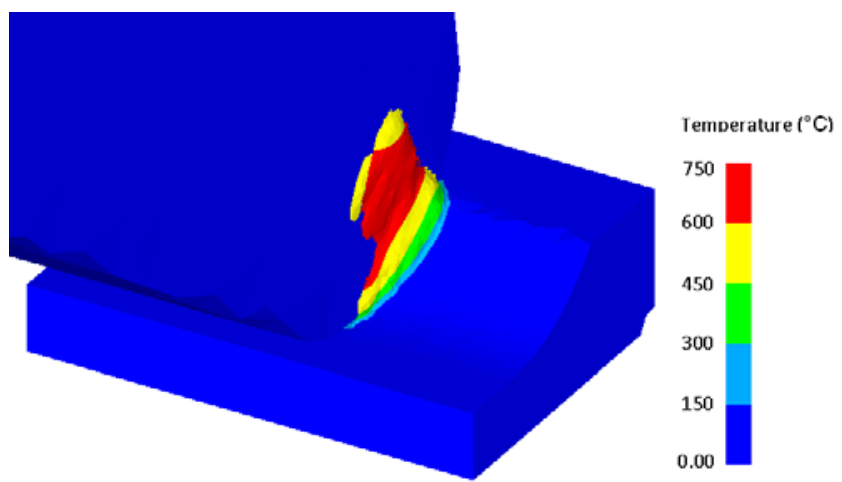

Figure 8: Temperature distribution in cutting region for UAT (frequency $20 \mathrm{kHz}$ and amplitude $30 \mu \mathrm{m}$ )

\section{Acknowledgement}

The research leading to these results has received funding from the European Union Seventh Framework Programme (FP7/2007-2013) under grant agreement No. PITN-GA-2008-211536, project MaMiNa.

Authors would also like to acknowledge Tampere University of Technology, Finland for providing material date of Ti alloy.

\section{References:}

[1] C. Brecher, C.J. Rosen, M. Emonts: 2010, Laser-assisted Milling of Advanced Materials. Physics Procedia, 5:259-272.

[2] A.V. Mitrofanov, V.I. Babitsky, V.V. Silberschmidt: 2004, Finite element analysis of ultrasonically assisted turning of Inconel 718., Vol. 153 154, pp. 233 239. Journal of Material Processing Technology, 153154:233-239.

[3] A.V. Mitrofanov, V.I. Babitsky, V.V. Silberschmidt: 2003, Finite element simulations of ultrasonically assisted turning. Computational Material Science, 28:645-653.

[4] N. Ahmed, A.V. Mitrofanov, V.I. Babitsky, V.V, Silberschmidt: 2006, Analysis of material response to ultrasonic vibration loading in turning Inconel 718. Materials Science and Engineering, A 424:318-325.

[5] N. Ahmed, A.V. Mitrofanov, V.I. Babitsky, V.V. Silberschmidt: 2007, 3D finite element analysis of ultrasonically assisted turning. Computational Materials Science, 39:149154.

[6] N. Ahmed, A.V. Mitrofanov, V.I. Babitsky, V.V. Silberschmidt: 2007, Analysis of forces in ultrasonically assisted turning. Sound and Vibration, 308:845-854. 
[7] N. Ahmed, A.V. Mitrofanov, V.I. Babitsky, V.V. Silberschmidt: 2006, Stresses in ultrasonically assisted turning. Applied Mechanics \& Materials, 5-6:351-358.

[8] A.V. Mitrofanov V.I. Babitsky, V.V. Silberschmidt: 2005, Thermomechanical finite element simulations of ultrasonically assisted turning. Computational Materials Science, 32:463-471.

[9] DEFORMTM 3D Ver 6.1, Scientific Forming Technology Corporation, Columbus, Ohio.

[10] A.V. Mitrofanov, N. Ahmed, V.I. Babitsky, V.V. Silberschmidt: 2005, Effect of lubrication and cutting parameters on ultrasonically assisted turning of Inconel 718. Materials Processing Technology, 162-163:649-654.

[11] A.J. Shih: 1996, Finite element analysis of orthogonal metal cutting mechanics. Machine Tools \& Manufacture, 36:255-273.

[12] Z. Li, J. Lambros: 1999, Determination of the dynamic response of brittle composites by the use of the split Hopkinson pressure bar. Computational Science Technology, 59:1097-1107.

[13] M. Demiral, A. Roy, V.V. Silberschmidt: 2010 (Submitted), Effects of loading conditions on deformation process in indentation. Computational Materials and Continua.

[14] H. Fassi, L. Bousschine, A. chaaba, A. Elharif: 2003, Numerical simulation of orthogonal cutting by incremental elastoplastic analysis and finite element methods. Material Processing Technology, 141:181188.

[15] T. Oezer: 2006, The influence of friction models on finite element simulations of machining. Machine Tools Manufacturing, 46:518-530.

[16] N. Ahmed, A.V. Mitrofanov, V.I. Babitsky, V.V. Silberschmidt: 2006, Stresses in Ultrasonically Assisted Turning. Applied Mechanics and Materials, 5-6:351-358. 